\title{
Whose shoes?
}

Imagine the situation where the busy NHS practitioner swapped with another dentist working in Whitehall or Wimpole Street, a magazine editor or even a hospital consultant for a week. . . it would be very revealing

Mike Grace m.grace.bdj@bda-dentistry.org.uk n

$n$ this issue of the BDJ I am publishing a letter by Dr Duncan Fitton that encapsulates a fairly common feeling among people the perception that other people have no idea what life is really like for each one of us. In this particular letter the main message appears to be that dentists in private practice, dental hospitals or not in practice at all (such as myself) are the ones that make the decisions for NHS GDPs without truly understanding what life in NHS practice is all about, and that if we were to try general NHS practice it would open our eyes to the reality.

While this is not the whole of the story, it is easy to understand the emotion behind it. We all tend to feel that no-one else understands us, and I can assure people that being an editor of a dental journal is not as easy as it looks ... but I digress. The important fact here is that this is the perception, and as we all know perception is all we have. Perception is the way we see the world, therefore it remains our version of reality. There are several points I would like to make about this matter. The first examines the wider picture, the second looks at who controls whom, and the third suggests a way of changing the perception (if people want to, which sometimes I doubt).

The author of the letter refers to a programme on BBC television in the UK called 'Back to the Floor' where managing directors of organisations and companies literally spend a week on the workshop floor to discover what life is like for the troops who have to do it every day. While I like the programme immensely, I am not sure that the analogy is true for NHS general dental practitioners. Firstly, they are not employees and have the ability to choose their own environment and secondly the private, hospital and desk-bound dentists referred to in the letter are hardly the 'bosses' of GDPs. A more appropriate television programme would surely be the one where individuals swap jobs, and that leads me to my second point.

Imagine the situation where the busy NHS practitioner swapped with another dentist working in Whitehall or Wimpole Street, a magazine editor or even a hospital consultant for a week. I suspect it would be very revealing for both of them, and here I agree with Mr Fitton completely. However, I suspect the NHS practitioner would have some prejudices questioned and would also gain a greater understanding about so-called 'dry-fingere6d dentists.' I have worked in NHS practice (admittedly some years ago now), I have worked in hospital, I have worked in the commercial world and I now work as an editor. All these situations have very different pressures, responsibilities, hours, difficulties and rewards. NHS practice was the most intense, but also had the shortest hours, the least responsibilities, the easiest requirements and the most control. The grass may always appear greener, but as those who try it know, this is not necessarily true. My final point concerns how we can change the perception that others control us, a perception that is particularly common for many GDPs as well as those in salaried employment. The truth is that each of us controls our own future, regardless of what others do, and especially in dentistry where we are free to choose a number of different career pathways and also a number of different remuneration systems (in general practice). Many of the decision-makers mentioned at the beginning of this leader are the ones fighting for us to retain that freedom, and to continue to do so well into the future.

Where I do agree with Dr Fitton is that it would do none of us any harm to 'walk a mile in the other person's shoes' and remind ourselves (or in some cases discover) what life is like for other people. But that applies to all of us, whether an academic, a GDP (private or NHS), a dental student, a deskbound dentist, a hospital consultant or a PCD — or even a magazine editor. 